\title{
LA DISTRIBUCIÓN DEL INGRESO EN EL GOBIERNO DE LA UNIDAD POPULAR
} (1970-1972)

\author{
Fernando CoRTÉs \\ $\mathrm{y}$ \\ RICARDO YocelEVZKY
}

\section{INTRODUCCIón}

ESTE TRABAjo se inscribe dentro de un proyecto de investigación cuyo objetivo central es conocer los determinantes económicos y políticos que están en la base del cambio de la distribución del ingreso en Chile, durante el período 1970-1972. Es una aplicación de un trabajo de carácter técnico-metodológico * que se propuso como objetivo la búsqueda de una técnica estadística que permitiera desagregar los movimientos experimentados por la distribución del ingreso, tanto en el tiempo como en el interior de los agregados estadísticos.

El presente escrito examina en profundidad los componentes de la política económica de la Unidad Popular, que hicieron posible una explicación de la dinámica de los ingresos monetarios de las distintas clases sociales de Chile en esa etapa. De todos modos, el análisis de la relación "política económica-distribución del ingreso" por sí sola resulta insuficiente para la comprensión del período estudiado. Sin embargo, la relación "política-política económica" excedería los límites que se han impuesto en esta etapa de la investigación. Un análisis de la situación política global que enmarque estos procesos será objeto de un estudio exhaustivo en un proyecto futuro.

La secuencia de las distintas etapas de la investigación no sigue un ordena arbitrario: se inscribe dentro de una conceptualización que considera que la dinámica de la distribución del ingreso está sujeta a determinaciones económicas y políticas. Aun cuando este tópico es materia de discusión coyuntural y conflicto político, creemos que las conclusiones afectarán tanto el análisis de la coyuntura, como las visiones estructurales del desarrollo de cada país.

Desde que el Estado se asume como generador del desarrollo de las economías latinoamericanas, la distribución del ingreso no puede ser

* Ackermann y Cortés: "Concentración y democratización: un alcance metodológico-técnico sobre el estudio de la distribución". 
considerada como un mero accidente, sino un resultado esperado de la aplicación de políticas económicas alternativas, que derivan de consideraciones económicas específicas (inflación, déficit de balanza de pagos, nivel y composición de la demanda, etc.) y de demandas sociales determinadas.

Las relaciones y prioridades establecidas entre estos elementos reflejan visiones ideológicas del desarrollo económico que emergen de una práctica social que es a la vez su origen y su límite. La coherencia de estas visiones no necesariamente se traduce en una práctica consistente, por cuanto su aplicación está históricamente determinada.

Aplicaremos el concepto de "modelo" para designar las visiones ideológicas de carácter general acerca del desarrollo, y denominaremos "estilos de desarrollo" a las prácticas que surgen de los intentos de aplicación de los "modelos" a situaciones en que éstos son redefinidos tanto por limitaciones sociales como por estructuras y procesos políticos particulares de cada situación histórica. En cada país el "estilo de desarro1lo" es definido por un conjunto de estructuras jurídicas e institucionales que determinan, por ejemplo, el grado de intervención del Estado en la economía y los órganos del Estado encargados de efectuarla. De manera complementaria queda delimitado el campo de la iniciativa privada.

El grado de rigidez institucional impuesto a un programa de desarrollo económico depende de la relación de fuerzas políticas en un momento dado. Esto ejemplifica la relación entre elementos del cambio estructural y los procesos coyunturales. Si la aplicación de una política económica de corto plazo (como la política de distribución de ingresos) que tiene por objetivo alterar la coyuntura se liga a un programa de transformaciones estructurales, entonces surge un problema de consistencia que no se puede resolver en base a consideraciones puramente económicas.

El desarrollo de las consideraciones precedentes aplicadas al período 1970-1972, será el objeto de análisis de este trabajo. Es de notar, que octubre de 1972 marca una alteración en la relación establecida entre coyuntura y estructura desde 1970, que privilegia los aspectos políticos por sobre los económicos, en la política de distribución de ingresos.

Este estudio, al asumir un enfoque explicativo predominantemente económico, deja fuera de su ámbito de análisis el período 1972-1973.

\section{Programa económico de la Unidad Popular y su formulación como política económica}

\subsection{Los aspectos económicos del programa de la Unidad Popular}

La estrategia económica de la UP surge como respuesta a la crisis chilena de fines de los años 60 . El diagnóstico de la misma se halla contenido en su Programa Básico de Gobierno: 
Chile vive una crisis profunda que se manifiesta en el estancamiento económico y social, en la pobreza generalizada y en las postergaciones de todo orden que sufren los obreros, campesinos y demás capas explotadas, así como en las crecientes dificultades que enfrentan empleados, profesionales, empresarios pequeños y medianos y en las mínimas oportunidades de que disponen la mujer y la juventud."

Las causas del estancamiento son expuestas en los siguientes términos:

Lo que ha fracasado on Chile es un sistema que no corresponde a las necesidades de nuestro tiempo. Chile es un país capitalista, dependiente del imperialismo, dominado por sectores de la burguesía estructuralmente ligados al capital extranjero, que no pueden resolver los problemas fundamentales del país, los que se derivan precisamente de sus privilegios de clase a los que jamás renunciarán voluntariamente.**

E1 diagnóstico identifica a los factores estructurales como determinantes del estancamiento económico, así como a las clases sociales que gozan de los beneficios del funcionamiento de este sistema.

La explicitación de las causas de la crisis económica impide una solución reformista:

En Chile las recetas "reformistas" y "desarrollistas" que impulsó la Alianza para el Progreso e hizo suyas el gobierno de Frei no han logrado alterar nada importante. En lo fundamental ha sido un nuevo gobierno de la burguesía al servicio del capital nacional y extranjero, cuyos débiles intentos de cambio social naufragaron sin pena ni gloria entre el estancamiento económico, la carestía y la represión violenta contra el pueblo. Con esto se ha demostrado, una vez más, que el reformismo es incapaz de resolver los problemas del pueblo.****

Al afirmar la imposibilidad de superar la crisis económica dentro del sistema capitalista, el programa plantea que:

La única alternativa verdaderamente popular $\mathrm{y}$, por lo tanto, la tarea fundamental que el gobierno del pueblo tiene ante sí, es terminar con el dominio de los imperialistas, de los monopolios, de la oligarquía terrateniente e iniciar la construcción del socialismo en Chile.****

En la lógica del Programa Básico de Gobierno de la Unidad Popular la transición al socialismo es la única solución al estancamiento económico y, por lo tanto, la única vía de desarrollo para la sociedad chilena. En

* Programa de la Unidad Popular, p. 3.

* Programa de la Unidad Popular, p. 4.

*** Programa de la Unidad Popular, p. 5.

*** Programa de la Unidad Popular, p. 11. 
consecuencia, se planteaba una política de desenvolvimiento económico cuyos objetivos eran:

1. cambio en la composición de la oferta a favor de los artículos de consumo popular y en contra de los productos suntuarios;

2. absorción de la desocupación;

3. expropiación del capital extranjero que operaba en los sectores estratégicos en el país;

4. uso máximo de las fuerzas productivas;

5. ejecución de una política de comercio exterior que redunde en un aumento y diversificación de la exportación; y,

6. control del proceso inflacionario.*

La consecución de estos objetivos dependía de la capacidad del Estado para planificar la economía. Como parte de esta tarea, se proponía una transformación de la estructura de la propiedad en un nuevo sistema que abarcaba: 1) el área de propiedad social, 2) el área de la propiedad privada y 3) el área mixta.

La primera se define como:

un área estatal dominante, formada por las empresas que actualmente posee el Estado más las empresas que se expropien.**

\section{La segunda:}

comprende aquellos sectores de la industria, la minería, la agricultura y los servicios en que permanece vigente la propiedad privada de los medios de producción. (...) Las empresas que integren este sector serán beneficiadas con la planificación general de la economía social. El Estado procurará las asistencias financiera y técnica necesarias a las empresas de esta área, para que puedan cumplir con la importante función que desempeñan en la economía nacional, atendiendo el número de las generan. $* * *$

Por último, la tercera (área mixta):

este sector será mixto porque se compondrá de empresas que combinen los capitales del Estado a los particulares.

De esta manera, los aspectos económicos del programa se organizan a partir del diagnóstico del estancamiento económico, se rechaza el reformismo y se sostiene que la transición al socialismo es la única solución.

* Programa de la Unidad Popular, pp. 28-30.

* Programa de la Unidad Popular, pp. 23-26.

**** Programa de la Unidad Popular, pp. 23-26. 
El logro de los objetivos se obtendrá con la alteración de las relaciones de propiedad, originándose así las tres áreas: estatal, privada y mixta.

\subsection{La politica económica de la Unidad Popular}

Establecidas las ideas centrales del programa corresponde examinar la manera como ellas se plasman en el modelo económico de corto y largo plazo.

La implementación de esta política económica implicaba, no sólo la aplicación de los principios estratégicos expresados en el programa, sino

Cuadro 1

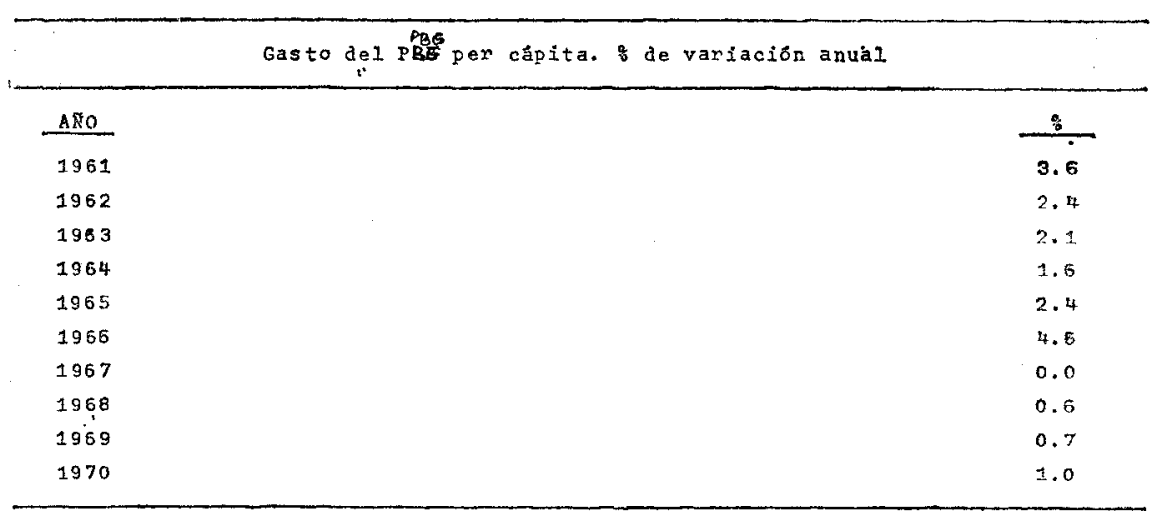

Fuente: ODEPLAN.

también una acción sobre la coyuntura económica que fuera coherente con los propósitos a largo plazo.

El diagnóstico de la situación económica para fines de 1970 contenía los parámetros que determinaron el diseño de la política económica a corto plazo. Se partía de una situación de estancamiento económico. Tal como lo muestra el siguiente cuadro, desde 1967 hasta 1970, la variación anual del gasto per capita establecida por el PBG (Programa Básico de Gobierno) no superaba el $1 \%$.

El estancamiento del crecimiento del producto coexistía con la disponibilidad de recursos productivos. La tasa de desocupación alcanzaba en el "Gran Santiago", el $7.9 \%$ de la fuerza de trabajo en junio de 1970; en Concepción y Talcahuano, el 10\%; y en Lota y Coronel, el $15.1 \%$ en abril del mismo año.* La capacidad instalada en la industria sólo era

* La Economía Chilena en 1971, pp. 71-72. Instituto de Economía, Universidad de Chile. 
Cuadro 2

INDICADORES DE UTILIZACIÓN DE LA CAPACIDAD INSTALADA EN IA INDUSTRIA ${ }^{3}$

\begin{tabular}{|c|c|c|c|}
\hline & 1967 & 1969 & 1970 (b) \\
\hline I. Industria de consumo habitual & 82.51 & 78.68 & 77.59 \\
\hline 20. Alimenticias & 83.19 & 77.70 & 75.45 \\
\hline 21. Bebidas & 87.26 & 74.02 & 66.69 \\
\hline 22. Tabaco & - & - & - \\
\hline 23. Textiles & 79.43 & 78.49 & 78.86 \\
\hline 24. Vestuario y calzado & 76.98 & 80.39 & 83.47 \\
\hline 26. Muebles & 7.8 .00 & 91.24 & 99.40 \\
\hline 28. Imprenta $g$ editorial & 74.24 & 80.06 & 81.57 \\
\hline 39. Diversas & 72.05 & 92.58 & 86.13 \\
\hline II. Industria de bienes fntermedios & 79.62 & 84.96 & 85.46 \\
\hline 25. Madera & 72.52 & 76.57 & 80.84 \\
\hline 27. Papel.y celulosa & 97.65 & 99.30 & 80.66 \\
\hline 29. Cuero & 71.69 & 68.82 & 72.41 \\
\hline 30. Caucho & 96.53 & 85.18 & 91.32 \\
\hline 31. QuImi cas & 62.50 & 80.91 & 83.33 \\
\hline 32. Derivados del petrb10o y carbón & 84.32 & 59.42 & 56.69 \\
\hline 33. Minerales no metálicos & 68.92 & 74.18 & 72.99 \\
\hline 34. Metálicas básicas & 80.52 & 69.45 & 92.68 \\
\hline \multirow{2}{*}{$\begin{array}{l}\text { IIx. Industria de bienes de consumo durable y capital } \\
\text { 35: Productos metalicos }\end{array}$} & 76.15 & 63.01 & 62.96 \\
\hline & 77.22 & 56.18 & 55.77 \\
\hline $\begin{array}{l}\text { 35. Productos metallecs } \\
\text {.36. Maquinaria no electrica }\end{array}$ & 80.91 & 75.99 & .70 .27 \\
\hline 37. Maquinaria eléctrica & 73.53 & 73.96 & 71.94 \\
\hline 38. Materiales de transporta & 78.00 & 62.11 & 68.73 \\
\hline Promedio sector & 80.65 & 75.64 & 75.34 \\
\hline
\end{tabular}

Fuente: ODEPLAN.

a Los datos corresponden a establecimientos que ocupan 50 o más personas.

El año 1970 corresponde a una estimación a partir de los datos del año 1969, utilizando indicadores de producción. 
utilizada en promedio en sus 3/4 partes. Además, las reservas de divisas alcanzaban el equivalente de casi $1 / 3$ de las importaciones anuales.*

La coyuntura económica se caracterizaba por una situación de recesión con una inflación que era la segunda más alta en el mundo, sólo superada por la de Vietnam del Sur.**

La contradicción entre el estancamiento económico y la disponibilidad de recursos productivos, se explicaba por la carencia de demanda efectiva. La estructura do la oferta reflejaba el crecimiento de la industria orientado hacia un mercado elitista, en virtud del grado de concentración del ingreso.***

Desde esta perspectiva, una opción. para quebrar las tendencias recesivas es la de recurrir al aumento de nivel de la demanda efectiva. Para lograr este objetivo se abren dos alternativas en relación al componente privado de la demanda: 1) reconcentrar el ingreso para dar mayor poder adquisitivo a los sectores sociales que generan una demanda coincidente con la estructura de la oferta; 2) redistribuir progresivamente el ingreso; esto implica un cambio en la composición de la demanda, que a su vez requiere alteraciones en la estructura de la oferta. En ambos casos se puede agregar al aumento de la demanda efectiva privada, un incremento de la demanda efectiva pública.

El gobierno de la Unidad Popular optó, de acuerdo con los principios establecidos en su programa, por la redistribución progresiva del ingreso, que unida a una política de gasto público con financiamiento deficitario,**** desembocó en un incremento considerable del nivel de la demanda efectiva y de la alteración de su composición. Esta estrategia requería un control eficiente de los precios; de no ser así, los mayores niveles de demanda de determinados tipos de productos, se traducirían en aumentos de precios. Al no corresponder las demandas y las ofertas desagregadas, el incremento en las primeras, controlando los precios, debía inducir a la reorientación del aparato productivo.

El aumento de los volúmenes de producción tendría tres efectos importantes: 1) disminución de la tasa de desocupación; 2) aumento del coeficiente de utilización de la capacidad instalada; y, 3) mayores requerimientos de divisas derivados de los coeficientes de importación de la industria chilena. Como se mencionara anteriormente, todos estos recursos estaban disponibles en 1970.

La aplicación del modelo suponía una respuesta positiva - aumento y cambio en la composición de la oferta- de los empresarios. Aun cuando la tasa de ganancia por unidad de producción disminuyera, ella se vería compensada por el aumento de volumen de las ventas. En efecto, al

* Ibid., p. 106

** Ibid., p. 73.

*** Ver Pedro Vuskovic: "Distribución del ingreso y opciones de desarrollo", p. 115.

**** Ibid., p. 102. 
someter el mercado a un control riguroso de precios además de redistribuir el ingreso en favor de las clases económicamente más desposeídas deberían necesariamente aumentar los costos de producción por unidad de producto; pero, al vender una cantidad apreciablemente mayor de bienes, la masa de ganancia tendería a ser restablecida o incluso a aumentar. De esta manera habría incentivos para que los empresarios realizaran inversiones marginales para reorientar el aparato productivo y también, en función de la racionalidad económica, elevar los niveles de inversión.

El éxito o fracaso de este modelo dependería básicamente de la capacidad del gobierno para sostener un crecimiento deficitario de la demanda pública y un cambio en el nivel y composición de la demanda privada, por vía de la redistribución del ingreso.

El gasto público es uno de los instrumentos tradicionales de la acción económica del Estado y el grado de control que ejerce el Ejecutivo sobre aquél es bastante alto así como legítimo. Sin embargo, existe un margen mayor de incertidumbre respecto a la capacidad del Estado para:

i) lograr una redistribución efectiva del ingreso; ii) que esta redistribución posea una intensidad acorde con las reacciones que se esperan del aparato productivo; y, iii) que el éxito logrado a través de la política de control de precios no produzca a posteriori una reconcentración del ingreso por vía de alteraciones del nivel y del sistema de precios.

Las consideraciones antepuestas obligan a privilegiar el estudio de las alteraciones de la distribución del ingreso, base de los cambios del nivel y composición de la demanda efectiva privada.

La política económica de largo plazo debería haber creado un área de propiedad social y mixta cuyo objetivo fuera aumentar la capacidad planificadora del Estado. La política de corto plazo proveería las condiciones que hicieran posible el avance de las transformaciones.*

Hasta aquí, el examen de las ideas centrales del programa econónico de la Unidad Popular y la aplicación de su modelo de corto y largo plazo. Las condiciones de viabilidad de las transformaciones estructurales se generarían a partir del fucionamiento del modelo de corto plazo, cuyo éxito o fracaso dependería, básicamente, de una redistribución progresiva del ingreso. En la sección siguiente se analizarán detenidamente los cambios experimentados por la distribución del ingreso entre los años 1970 y 1972.

\section{La politica redistributiva del gobierno de la UP}

\subsection{Introducción}

Los cambios producidos en la concentración del ingreso de las distintas categorías ocupacionales, como consecuencia de la aplicación de la polí-

* Ibid., pp. 88-89. 
tica económica de la UP entre 1970 y 1972, son el núcleo del presente estudio.

Los datos presentados se refieren a Santiago, capital del país. Provienen de la "Encuesta de ocupación y desocupación" que trimestralmente realiza el Instituto de Economía de la Universidad de Chile. En este caso se utilizó la encuesta llevada a cabo durante el mes de junio de

Cuadro 3

Distribución de la Fuerza dE TRABAjo SEgúN LA RAMA DE ACTIVIDAD ECONÓMICA. 1970

\begin{tabular}{|c|c|c|c|c|c|c|c|}
\hline $\begin{array}{l}\text { Ramas de } \\
\text { actividad economica }\end{array}$ & $\begin{array}{l}\text { Gran } \\
(1)\end{array}$ & $\operatorname{san}$ & $i a g$ & & $\begin{array}{l}\text { sto deI } \\
\text { 2) }\end{array}$ & 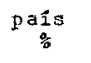 & $\begin{array}{l}\text { Porcentaje; } \\
100(1) /(2)\end{array}$ \\
\hline $\begin{array}{l}\text { 1. Agricultura, silíicultura, } \\
\text { caza y pesca }\end{array}$ & 11 & 880 & 1.4 & 540 & 460 & 30.9 & .2 .2 \\
\hline $\begin{array}{l}\text { 2. Explotación de minas y can } \\
\text { teras }\end{array}$ & 2 & 760 & 0.3 & 72 & 540 & 4.1 & 3.7 \\
\hline 3. Industria Manufacturera & 204 & 660 & 23.9 & 210 & 780 & 12.0 & 97.3 \\
\hline $\begin{array}{l}\text { 4. Iuz, gas, agua y servicio } \\
\text { sanitario }\end{array}$ & 9 & 720 & \pm .1 & 11 & 560 & 0.6 & 84.1 \\
\hline 5. Construcción & 53 & 540 & 6.2 & 94 & 960 & 5.4 & 56.4 \\
\hline 6. Comercio & 130 & 640 & .15 .3 & 172 & 460 & 9.9 & 75.8 \\
\hline $\begin{array}{l}\text { 7. Transporte, alnacenaje y } \\
\text { :comunicaciones }\end{array}$ & 51 & 840 & 6.0 & 103 & 680 & 5.9 & 50.0 \\
\hline 8. Establecimientos financieros & 25 & 060 & 2.9 & 16 & 920 & 1.0 & 148.1 \\
\hline 9. Servicios & 283 & 280 & 33,0 & 384 & 260 & 22.0 & 73.7 \\
\hline $\begin{array}{l}\text { 10. Actividades no bien especi-" } \\
\text { ficadas }\end{array}$ & 84 & 540 & 9.9 & 141 & 820 & 8.1 & 59.6 \\
\hline TOTAL & 857 & 920 & 100.0 & 1749 & 440 & 100.0 & 49.0 \\
\hline
\end{tabular}

Fuente: INE-CELADE. Muestra de adelanto de las cifras del Censo de Población de Chile, 1970.

1970, 1971 y 1972, en el estado en que son presentados por Arturo León.* Esta información posee significación limitada, ya que proviene de una muestra tomada casi exclusivamente de zonas urbanas. Sin embargo, su realización permitió aproximar datos empíricos a una interpretación de la distribución del ingreso según las categorías ocupacionales.

Las distorsiones que presenta la población de Santiago con respecto al conjunto del país son observables, fundamentalmente, en la distribución de la fuerza de trabajo según las ramas de la actividad económica.

En la muestra del Gran Santiago, la rama de actividad "agricultura,

* Arturo León. "Antecedentes para el análisis de la distribución personal y familiar del ingreso". Chile, 1970-73. 
silvicultura, caza y pesca", está sub-representada respecto del resto de las ramas debido a que la muestra es urbana; como contrapartida, se observa una sobre-representación de las ramas "industria manufacturera" y de "servicios", que denota el carácter fundamentalmente industrial de la ciudad de Santiago, sede, por otra parte, de la burocracia estatal central. Estas distorsiones también se reflejan en la distribución de la fuerza de trabajo según las categorías de ocupación.

\section{Cuadro 4}

Distribución de la FuERza de trabajo SEgón LA CATEGoría OCUPACIONAL. 1970

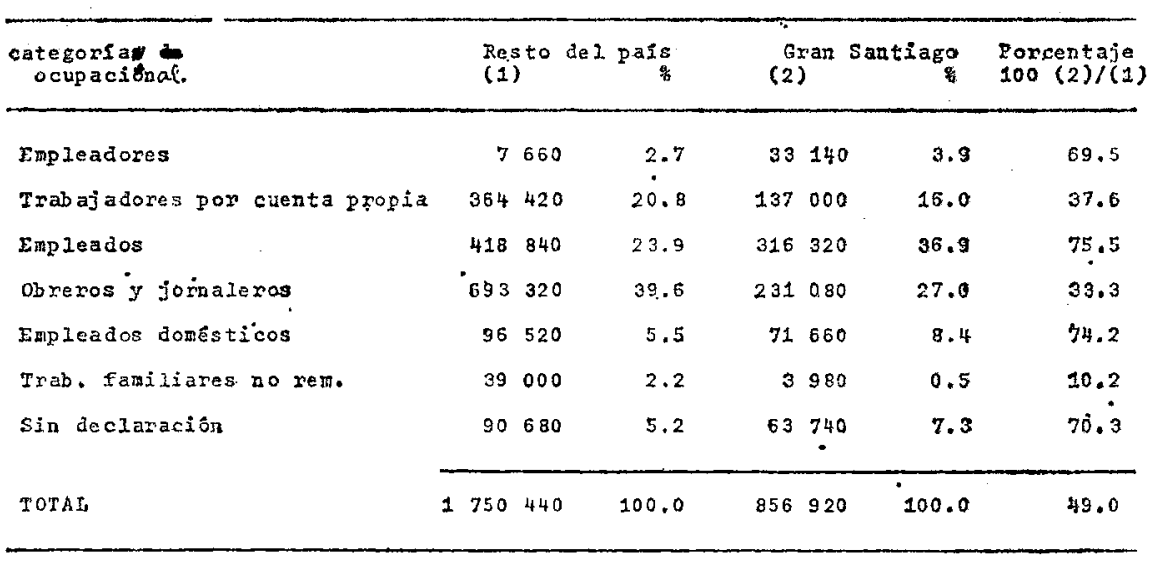

Fuente: INE-CELADE, op. cit.

En esta distribución, en Santiago están sub-representadas las categorías de "trabajadores por cuenta propia", "obreros y jornaleros" y "trabajadores familiares no remunerados", debido a la ausencia casi absoluta del sector rural en la zona del Gran Santiago. Por lo tanto, el análisis no dará cuenta del campesinado así como de ninguna otra ocupación desarrollada en el sector rural.

Las categorías: "empleados", "empleados domésticos" y "empleadores" aparecen en Santiago con un mayor peso del que tienen en el resto del país, debido a la concentración de la industria y los servicios en esta zona. Es probable que "obreros" esté sobre-representado en la muestra, hecho difícil de precisar dada la agregación de que ha sido objeto esta categoría y la de "jornaleros agrícolas" en el resto del país.

Las cifras disponibles impiden ampliar el análisis a la totalidad de la economía chilena, no obstante se presentará un cuadro confiable del comportamiento de las variables en las zonas urbanas.

En lo referente a la cobertura del estudio, es preciso notar que la po- 
blación de Santiago representa casi un tercio del total de la población del país con doce años y más de edad.

Los cambios de la distribución del ingreso a lo largo del tiempo, tratados de acuerdo con las categorías ocupacionales, han sido analizados según el teorema de descomposición de la varianza de Ackermann y Cortés.*

2.2. Cambio en la distribución del ingreso según la ocupación, entre 1970 y 1971

El siguiente cuadro resume los movimientos de las categorías ocupacionales según sea su participación en la distribución del ingreso.

\section{Cuadro 5}

DEscomposición DE LA VARIABILIDAD DEL INGRESO ENTRE 1970-1971 CORREGIDO POR EFECTO DE ESCALA

\begin{tabular}{|c|c|c|c|}
\hline $\begin{array}{l}\text { Categonfa } \\
\text { Ocupacional. }\end{array}$ & $\begin{array}{l}\text { Varianza } \\
\text { total }\end{array}$ & Intervarianza & Intravarianza \\
\hline obrenos & 0.0286 & 0.0171 & 0.0115 \\
\hline Enpleàdos & 0.1371 & -0.0175 & 0.1546 \\
\hline Irabajadares por cuenta propia. & 0.0523 & -0.0044 & 0.0567 \\
\hline Empleadores & 0.4643 & 0.2772 & 0.1871 \\
\hline TFAA & -0.0031 & -0.0006 & -0.0025 \\
\hline Etmpl. domesticos & 0.0059 & -0.0019 & 0.0078 \\
\hline Totales & 0.6851 & 0.2699 & 0.4151 \\
\hline
\end{tabular}

Estos valores son el resultado de restar de las varianzas de 1970 sus correspondientes a 1971 (total, intra e inter). Los valores positivos indican una tendencia hacia la equidistribución, ya que reflejan un acercamiento de las observaciones al valor promedio. Es decir, los datos para 1971 están más próximos a su media que los de 1970. Un valor negativo obtenido como resultado de esta operación indica una tendencia al alejamiento con respecto al promedio y por lo tanto, una mayor concentración del ingreso.

Para aquellas categorías ocupacionales situadas sobre el promedio, el resultado positivo indica un retroceso relativo de su posición en la distribución del ingreso, ya que la aproximación al promedio implica una

* Ackermann y Cortés: op. cit. 
disminución de su participación. Inversamente, en el caso de las categorías ocupacionales ubicadas debajo de la media, el resultado positivo obtenido luego de la sustracción, indica un avance de su posíción relativa, ya que aproximarse al promedio significa haber aumentado su participación en la distribución del ingreso.

También los valores negativos son posibles de una doble interpretación. El alejamiento del promedio significa una mejora en la situación de las categorias ubicadas sobre el promedio, como consecuencia de su mayor participación en el ingreso. Caso contrario, el alejamiento de una categoría ubicada debajo del promedio indica una disminución relativa de su participación.

La interpretación anterior será válida tanto para este cuadro como para el conjunto de cuadros integrados por valores de varianzas * que se presentarán a continuación.

En la columna de la varianza total del cuadro núm. 5, se puede observar una tendencia general a la igualación, es decir a una equidistribución, reflejada por el total de la columna $(0.6851)$. Los valores positivos de las categorías ocupacionales, con excepción de la de "FFAA" (único valor negativo), indican que la participación de todas ellas se movió en dirección a una equidistribución. Del aporte de cada una de las categorías a este movimiento de equidistribución, se destaca el realizado por la de "empleadores" (0.4643), cuya participación en el ingreso disminuyó. En segundo término aparece la de "empleados" (0.1371) con el empeoramiento relativo de su participación. Los movimientos de las categorías "obreros" y "trabajadores por cuenta propia" son pequeños, y mínimos en el caso de la de "FFAA" y "empleados domésticos".

La línea de los totales indica que el proceso de igualación surge fundamentalmente de la tendencia a la homogeneización en el interior de cada ocupación, que se refleja en el total de la columna intravarianza (0.4151). Secundariamente la línea de los totales muestra $(39.4 \%)$, el aporte que hacen las posiciones relativas de las categorías ocupacionales a la distribución progresiva del ingreso. (Observar la columna intervarianza (0.2699)). Esta descomposición de los cambios en la distribución del ingreso es la resultante de los movimientos de las ocupaciones. Así, "empleadores" se caracteriza por ser la única categoría que experimentó un cambio, que fue más importante en su posición relativa que en su composición interna (intervarianza: 0.2772 , intravarianza: 0.1871 ). Estos valores nos permiten inferir que el aporte que hace "empleadores" a una distribución más democrática del ingreso se debe, principalmente á un retroceso de su participación en el total. Sin embargo, es interesante notar que también se produce un movimiento de igualación en el interior

* En realidad se trata de varianzas corregidas por efecto escala, pero por razones de redacción seguiremos utilizando el término varianza. 
de esta categoría, que en combinación con el efecto anterior, otorga significación al movimiento general.

En las restantes categorías (con excepción de "obreros" cuyos cambios son pequeños y además se descomponen en valores casi equivalentes (intervarianza 0.0171, intravarianza 0.0115) ), es más importante el cambio dentro de la categoría que el experimentado por su posición relativa.

Articulando la lectura anterior con la de la columna intervarianza (donde el total prácticamente coincide con el valor para la categoría "empleadores"), se puede concluir que la aplicación de la política económica del gobierno de la Unidad Popular en el período considerado afectó fundamentalmente a los empleadores.

Cuadro 6

CONTRIBUCIÓN DE CADA TRAMO DE SUELDO VITAL A LA VARIACIÓN DE LAS INTRAVARIANZAS (1970-1971)

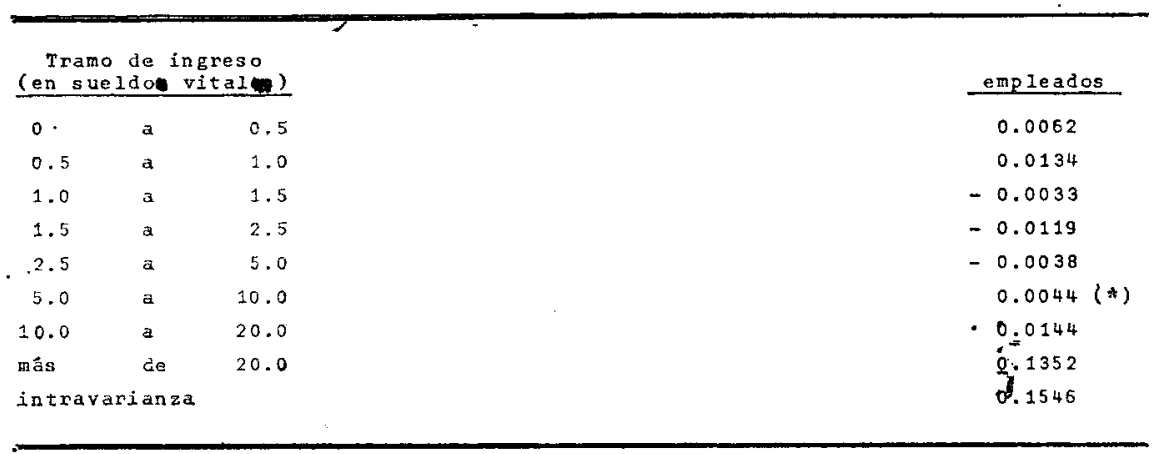

* Ubicación de la media.

El caso de la categoría "empleados", es más complejo que la de "empleadores". Por una parte, se da un avance relativo del grupo (intervarianza negativa $(-0.0175)$, como resultado del alejamiento de su media ${ }^{2}$ del promedio general, contribuyendo así a la desigualdad. Sin embargo, en su varianza total, este movimiento queda oculto por la importencia que adquiere la tendencia a la mayor equidad interior, que se refleja en una intravarianza positiva $(0.1546)$. Este doble movimiento que afecta a la categoría "empleados" entre 1970 y 1971 permite ilustrar sobre las posibilidades de la metodología propuesta para desarrollar el análisis de una categoría ocupacional a nivel de cambios internos. Este caso será presentado aquí como patrón. Los valores para cada categoría se insertan en el apéndice núm. 1.

1 Es de notar que entre ambas agotan los cambios significativos ocurridos en la distribución del ingreso.

2 Es una categoria que se ubica por encima de la media general. 
La tabulación de la variable "ingresos" (de acuerdo con la información disponible), se presenta agrupada por tramos de sueldo vital. Los datos del cuadro que se expone a continuación se obtienen al restar el aporte de cada tramo de ingreso a las intravarianzas para el período 1970 1971.

Como hemos visto, los empleados como grupo, tienden a hacer un aporte leve a la concentración del ingreso (intervarianza). Sin embargo, la contribución significativa se da en sentido contrario a la equidistribución en el conjunto (varianza total del grupo). Lo anterior se explica por los cambios que ocurren en su distribución interna (intravarianza). E1

\section{Cuadro 7}

DISTRIBUCIÓN DEL INGRESO REAL PROMEDIO EN JUNIO DE CADA AÑO EXPRESADO EN E ${ }^{\circ}$ DE JULIO DE $1970^{*}$

\begin{tabular}{|c|c|c|c|c|}
\hline \multirow{2}{*}{$\begin{array}{l}\text { Categoria } \\
\text { Ocupacional }\end{array}$} & \multicolumn{2}{|c|}{ En $E^{\circ}$ de juIio/70 } & \multicolumn{2}{|c|}{ Indice julio/70 $=100$} \\
\hline & 1970 & . 1971 & 1970 & 1971 \\
\hline obreros & 809.3 & 988.3 & 100.0 & 122.1 \\
\hline Empleados & $2,381.3$ & $2,892.3$ & 100.0 & 121.5 \\
\hline Trabajadores por cuenta propia & $1,536.9$ & $1,664.7$ & 100.0 & 108.3 \\
\hline Emp leadores & $8,822,5$ & $6,517.0$ & 100.0 & 73.9 \\
\hline FFAA & $1,923.4$ & $2,541.2$ & 100.0 & 132.1 \\
\hline Eng I. domésticos & 698.6 & 778.7 & 100.0 & 111.5 \\
\hline TotaI & $1,705.1$ & $3,022.3$ & 100.0 & 118.6 \\
\hline
\end{tabular}

proceso de homogeneización interna se debe (de acuerdo a la información proporcionada por el cuadro anterior), a que los seis tramos superiores sufren un descenso de posición relativa dentro del grupo (nótese la ubicación del promedio), en tanto que los dos tramos más bajos mejoran su posición relativa.

Este análisis permite ubicar a las categorías ocupacionales en sus posiciones relativas dentro de la distribución, así como describir los movimientos de los distintos tramos de ingreso en el interior de cada ocupación. Este tipo de análisis no permite conocer si una categoría ocupacional determinada ha empeorado o mejorado su posición absoluta en el curso del tiempo. Para ello habría que comparar la variación en el ingreso real. Así, por ejemplo, conjuntamente con la alteración de su posición relativa y los cambios internos, la categoría "empleados" experimentó un incremento de su ingreso real promedio del orden del $21.5 \%$.

* $\mathrm{E}^{\circ}=$ escudo, unidad monetaria chilena. 
El cuadro que se mostrará a continuación, muestra los movimientos del salario real, en escudos de 1970, para las seis categorías ocupacionales.

Hasta aquí se ha expuesto en detalle la utilización de la información proporcionada por el cuadro de descomposición de la varianza del ingreso (cuadro núm. 5) y por el cuadro de contribución de cada tramo de sueldo vital a la variación de las intravarianzas para el caso de la categoría "empleados". En base a la información contenida en dichos cuadros, además de la que se incluye en el apéndice núm. 1 y la entregada por el cuadro de salario real promedio, se resumirán los movimientos principales que afectaron la participación en el ingreso de las diferentes ocupaciones. No serán incluidos los análisis de "empleadores" ni de "empleados" por significar una repetición.

La categoría "obreros" refleja un aumento del salario real de orden del $22.1 \%$. El movimiento de esta categoría permite inferir una equiparación relativa en la distribución del ingreso (que se descompone en partes aproximadamente iguales) al mejorar la participación obrera respecto de las otras categorías, así como la equidistribución interna. Asimismo, en el interior de la categoría se produce una concentración en torno al promedio de todos los tramos de ingreso.

En resumen, durante el período 1970-1971, los obreros obtuvieron una mejora tanto en términos absolutos como relativos comparativamente con los otros sectores. Por otra parte, dentro del grupo hubo una tendencia a una distribución más igualitaria.

El ingreso real promedio para la categoría "trabajadores por cuenta propia" expresó un aumento en el período de un $8.3 \%$. Su aporte a la equiparación de la renta es relevante por cuanto ocupa el tercer lugar, pero es muy inferior al de "empleados", que ocupa el segundo lugar. Esta contribución resulta fundamentalmente de un proceso de equidistribución interna y de manera marginal, de la pérdida de su posición relativa respecto del resto de las categorías. El aporte más significativo de esta categoría a la democratización de la distribución del ingreso se debe, básicamente, a la pérdida de la posición relativa de los tramos de más de 10 escudos de sueldo vital ${ }^{1}$ y a una mejora más o menos importante de los dos tramos de menor sueldo vital.

Durante el período 1970-1971, la categoría "fuerzas armadas" registró el alza más importante (respecto a las restantes categorías) de su ingreso real promedio, el cual ascendió un $32.1 \%$. En oposición a las restantes ocupaciones, esta categoría contribuyó a la distribución regresiva del ingreso, que se descompone principalmente en una concentración interna y secundariamente, en una mejora de su posición relativa en relación a las otras ocupaciones.

Es importante observar en el apéndice núm. 1, que el tramo superior de ingresos de "fuerzas armadas" (5 a 10 escudos de sueldo vital) se ale-

1 Ver Apéndice № 1. 
ja del promedio, mientras que los dos tramos inmediatamente inferiores ( $3^{\circ}$ y $4^{\circ}$ tramos) pierden su posición relativa dentro del grupo, alejándose en forma descendente del promedio.

Ésta es la única categoría ocupacional que experimentó movimientos en dirección contraria a los sufridos por las otras. En efecto, no sólo mejoró su posición relativa en la distribución general, sino que también la estructura jerárquica interna se vio reforzada por una distribución aún más desigual del ingreso.

El ingreso real expresado por la categoría "empleados domésticos" subió un $11.5 \%$ entre 1970 y 1971 . La misma indica el aporte más pequeño al movimiento de equiparación general, que se explica fundamentalmente por una mejor distribución interna. Sin embargo, hay que destacar que experimentó una pérdida de su posición respecto de las otras categorias ocupacionales. Asimismo muestra un retroceso respecto a la media general (intervarianza negativa ubicada por debajo de la media).

Todos los tramos de ingreso de la categoría "empleados domésticos" expresan el movimiento de equiparación interno que generan los dos tramos superiores ( 5 a 10 y 10 a 20 escudos de sueldo vital).

De este análisis de la distribución del ingreso entre 1970 y 1971, se pueden extraer las siguientes tendencias:

1. Todas las ocupaciones, excepto la de empleadores, vieron aumentado, en términos absolutos, su ingreso real promedio.

2. Hay un movimiento hacia una distribución más equitativa del ingreso.

3. Los cambios de las posiciones relativas de las categorías ocupacionales (intervarianzas) se resumen en la siguiente tabla:

Tabla 1

CAMBIO dE LAS POSICIONES RELATIVAS DE LAS CATEgoRías OCUPACIONALES (1970-1971)

\begin{tabular}{llllll}
\hline & \multicolumn{2}{c}{ Mejoran } & \multicolumn{2}{c}{ Empeoran } \\
\hline Originalmente por debajo de la media & Obreros & $(+)$ & $\begin{array}{l}\text { Trab. } \times \text { CP } \\
\text { Empleados } \\
\text { domésticos }\end{array}$ & $(-)$ \\
$\begin{array}{l}\text { Originalmente por encima de la media } \\
\text { general }\end{array}$ & $\begin{array}{l}\text { Empleados } \\
\text { FFAA }\end{array}$ & $(-)$ & Empleadores & $(+)$ \\
\hline
\end{tabular}

4. El $60.6 \%$ del movimiento general de equiparación se debe a un proceso de homogeneización dentro de cada categoría (intravarianzas), excepto en el caso de "fuerzas armadas" donde se produce una mayor concentración. 
5. En base a la información del apéndice núm. 1, se puede afirmar que, excepto en la categoría "empleadores", en todas las categorías los tramos inferiores de sueldo vital mejoran su posición relativa en tanto que los tramos superiores de sueldo vital sufren una pérdida de posición relativa interna (excepción hecha de "empleadores" y "fuerzas armadas").

Una primera observación surge del resumen anterior: en términos generales, estos cambios son consistentes con los objetivos manifiestos de la política económica de corto plazo aplicada por el gobierno de la Unidad Popular.

En el programa de reactivación económica, el aumento del ingreso real era un prerrequisito fundamental para actuar sobre la demanda efectiva.

El análisis de la tendencia muestra una redistribución progresiva del ingreso, vincula a la reorientación esperada de la demanda. La mejora relativa de los tramos inferiores de ingreso, dentro de cada categoría, tanto como el acercamiento de los tramos superiores al promedio, confirman el éxito de los mecanismos de la política económica de la UP, aplicados para estimular la demanda masiva y limitar la de carácter elitista.

Sin embargo, se plantea un interrogante respecto a "empleadores": ison los resultados observados concordantes con los objetivos fijados por la política económica de la UP? Los cambios observados en la posición relativa de esta categoría son consistentes con los objetivos, ya que la política del gobierno chileno requería el aumento de la participación de otras categorías; en cambio, el deterioro absoluto del ingreso real promedio de "empleadores" difícilmente se puede desprender de los objetivos explícitos del programa de reactivación económica. Si bien un objetivo declarado del programa era disminuir la tasa de ganancia por unidad de producto, se esperaba que con el aumento de los volúmenes de producción, estimulados por la demanda adicional, la masa de ganancia no se vería sustancialmente afectada. Sin embargo:

La severa aplicación del sistema de controles convencionales, además del apoyo creciente del área de propiedad social y mixta, permitió contener el aumento de los precios al consumidor a sólo $22.1 \%$ entre los meses de diciembre de 1970 y 1971. Las empresas pudieron absorber una parte importante de los aumentos de salarios por una disminución de las ganancias parcialmente * recuperados por los aumentos de las ventas.**

El éxito de la política de control de precios y de la política de remuneraciones explica los cambios experimentados por las categorías "obreros", "empleados" y "fuerzas armadas".

'Según el Instituto de Economía de la Universidad de Chile, las principales disposiciones de la ley de reajuste de sueldos y salarios de 1971 (ley núm. 17416) fueron:

* Subrayado nuestro.

** Alberto Martínez: El área de propiedad social y mixta (APSM) del sector industrial durante el gobierno de la UP, p. 60. 
a) Para todos los sectores se establecía un reajuste mínimo de remuneraciones equivalente al $100 \%$ del alza del costo de la vida registrado durante 1970 (34.9\% según el índice de precios al consumidor enero a diciembre); b) se eleva el salario mínimo de $\mathrm{E}^{\circ} 12.00$ diarios a $\mathrm{E}^{\bullet} 20.00$, 10 que implicaba un aumento del $66 \%$ para los ubicados en estos tramos; c) se reajustaron las remuneraciones menores $o$ iguales a un sueldo vital en un $39.9 \%$, por la aplicación de cinco puntos de por ciento adicionales al aumento del costo de la vida durante $1970 ; d$ ) se reajustaron las remuneraciones entre 1 y 2 sueldos vitales en un $37.9 \%,-3$ puntos por ciento adicionales; e) las asignaciones por carga familiar fueron reajustadas de $\mathrm{E}^{\circ} 68.00$ a $^{\circ} 102.00$ para los empleados públicos. Para las FFAA y Carabineros, la asignación fue elevada de $\mathrm{E}^{\circ} 1.50$ a $\mathrm{E}^{\circ} 3.00$ diarios por carga. Para todos los restantes sectores de trabajadores - que poseían asignaciones familiares más altas-, fueron reajustadas siguiendo el alza del costo de la vida.*

Los datos analizados en este estudio reflejan los efectos de la aplicación de estas medidas. El reajuste general señalado en el inciso a) de la disposición, se refiere al alza general del ingreso de los obreros, empleados y FFAA.* Los incisos b) a c) tornan comprensible la tendencia a la equidistribución que se da en el interior de estas categorías ocupacionales, especialmente en lo referente a los tramos más bajos de ingreso.

La participación de los empleados domésticos en la distribución del ingreso difícilmente puede ser explicada por leyes que fijan los salarios. La práctica indica que generalmente éstas no se cumplen. Cabe recordar que esta categoria ocupacional expresó un incremento de su ingreso real promedio del orden del $11.5 \%$, cifra inferior a la registrada por el alza general de los ingresos reales, durante 1971 (18.6\%). En términos de posición relativa tanto en relación con las categorías ocupacionales como dentro de la misma, los cambios son insignificantes.

Es difícil comprender lo ocurrido con "trabajadores por cuenta propia" si no se considera la heterogeneidad de la misma. Esta categoría ocupacional ha sido definida como:

Toda persona que ejerce sus actividades en forma independiente, sin estar afecto a las disposiciones del Código del Trabajo y que no cuenta con más de dos personas contratadas bajo su dependencia, excluidos los familiares no remunerados.***

Esta definición permite ubicar en la misma categoría estadística a un vendedor ambulante, un floreciente pequeño artesano, o a los profesionales liberales. Su heterogeneidad muestra el comportamiento errático de los tramos de ingreso de los componentes de la categoría.

* Inst. Ec., Univ. Chile: La Ec. chilena/71, pp. 114-115,

** Las FFAA fueron sólo parcialmente afectadas por esta ley (en lo que se refiere a sus asignaciones familiares) ya que sus remuneraciones fueron objeto de una ley especial.

*** Arturo León: Op. cit., p. 130. 
El análisis de este período permite sostener que, en términos generales, la aplicación de los instrumentos de la política económica de corto plazo de la UP fue exitosa, especialmente en el logro de la adecuación entre los objetivos planteados en términos de la demanda y los resultados obtenidos. Se logro: a) un alza importante del nivel de ingresos real promedio; b) un incremento de la demanda efectiva; $c$ ) una redistribución progresiva del ingreso en favor de los estratos de más bajos ingresos; d) estos últimos incidieron en la composición de la demanda.

Queda fuera de los límites de este estudio el análisis del comportamiento de la oferta frente a los cambios de nivel y composición de la de-

Cuadro 8

DESOOMPOSICIÓN DE LA VARIANZA DEL INGRESO ENTRE 1971-1972 CORREGIDO POR EFECTO ESCALA

\begin{tabular}{|c|c|c|c|}
\hline $\begin{array}{l}\text { Categorisa } \\
\text { Ocupacional } \\
\text {. }\end{array}$ & varianza total" & intervarianza & intravarianza \\
\hline obrero6 & 0.0073 & 0.0119 & -0.0046 \\
\hline Enpleados & 0.2317 & 0.0294 & 0.2023 \\
\hline Trabajacores por cuenta propia & 0.0008 & 0.0044 & -0.0036 \\
\hline Emp leadores & 0.0747 & 0.0348 & 0.0399 \\
\hline FFAA & 0.0011 & -0.0009 & -0.0020 \\
\hline \multirow[t]{2}{*}{ Emp 1. domésticos } & 0.0075 & 0.0092 & $\therefore 0.0017$ \\
\hline & 0.3231 & 0.0888 & 0.2343 \\
\hline
\end{tabular}

manda, la incidencia sobre el nivel de empleo y utilización de la capacidad instalada, pues implicaría hacer la evaluación global de la política económica de la Unidad Popular.*

\subsection{Cambios en la distribución del ingreso según la categoría ocupacional entre 1971 y 1972}

Esta sección estará limitada a la exposición general de los datos y tendencias principales observadas durante el período 1971-1972.

En este cuadro se observa, que durante el período, si bien persiste la tendencia a la distribución más equitativa del ingreso, se profundiza la equiparación dentro de las categorías ocupacionales (la intravarianza pasa de un $60 \%$ de la varianza total en $1970-71$ a un $72.5 \%$ en $1971-72$ ).

* Respecto de este tema: Stefan de Vylder: Allende's Chile: the Political Economy of the Rise and Fall of the Unidad Popular. 
Nuevamente "empleados" y "empleadores" muestran la mayor contribución al movimiento general pero esta vez el aporte indicado por "empleados" supera largamente al de "empleadores". Al examinar la columna de las varianzas totales encontramos que la suma para ambas categorías

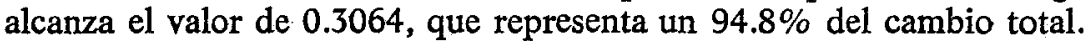

Por otra parte, "empleados" señala que la equiparación se produce sustancialmente dentro del grupo (intravarianza 0.2023) y subsidiariamente se da una caída de su posición relativa (intervarianza 0.0294). En el caso de "empleadores", éste destaca un doble movimiento de magnitudes casi equivalentes, de la pérdida de posición relativa (intervarianza 0.0348) y la tendencia a la equidistribución interna (intravarianza 0.0399).

Los indicadores usados señalan cambios fundamentales durante el periodo: i) la categoría "empleadores" indica la misma tendencia que en el período 70-71, aunque bastante atenuada; ii) "empleados" señala un cambio de dirección del movimiento de su posición relativa en 1971-72 con respecto al período anterior; y iii) ambas ocupaciones muestran una marcada tendencia a la igualdad interna.

Examinadas las características globales para "empleados" y "empleadores", se analizará la distribución interna de las variables según los tramos de sueldo.

El movimiento de homogeneización de "empleados" se debe principalmente, a la caída en dirección al promedio del tramo superior (más de $20 \mathrm{E}^{\circ}$ vitales), reforzada por una leve tendencia a la concentración en torno a la media.

Para "empleadores" el proceso de equidistribución interna se debe básicamente a la caída hacia el promedio de los dos tramos superiores (más de $10 \mathrm{E}^{\circ}$ vitales) y por una leve alza de los cinco tramos inferiores.

A los movimientos relativos se agrega la caída del ingreso real promedio de estas dos categorías entre 1971 y 1972. Es decir, no sólo pierden posición relativa con respecto a las otras ocupaciones y se produce una equiparación interna sino que sufren además, una pérdida de ingreso real promedio respecto del de 1971.

A continuación se presentará un resumen del comportamiento denotado por las restantes categorías, basado en la información referida a ingreso real promedio y a los datos contenidos en el apéndice núm. 2.

El ingreso real promedio de "obreros" denota un alza del $10.9 \%$ entre 1971 y 1972. Esta categoría señala la existencia de un movimiento tendiente a la igualación, que es más leve que la del período inmediatamente anterior. Este movimiento consta por una parte, de una mejora denotada por la porción de la categoría "obreros" respecto a las restantes y por otra, por una leve tendencia a la concentración del ingreso en el interior de la categoría, producto de la polarización interna de sus ingresos. Asimismo se observa un deterioro relativo de cuatro de los tramos inferiores de ingreso (con excepción del último tramo) y una mejora de los dos tramos superiores. 
El ingreso real promedio de "fuerzas armadas" denota el alza más elevada de todas las categorías durante el período $(17.2 \%)$. El grupo en su conjunto contribuye al movimiento de igualación general, fruto de la distribución interna del ingreso más equitativa; por otra parte, la posición relativa de la categoría continúa mejorando.

Una distribución más democrática del ingreso denota "fuerzas armadas". Los tramos de sueldo vital en su conjunto se movieron en dirección al promedio, excepto el tramo superior que se alejó. Tanto la mejora absoluta del ingreso promedio del grupo como la de su posición relativa respecto a las otras ocupaciones, se refleja en el desplazamiento del conjunto de la distribución.

\section{Cuadro 9}

Distribución dEL INGRESO REAL PROMEDIO DE JUNIO DE CADA AÑo EXPRESADO EN E $E^{\circ}$ DE JULIO DE 1970

\begin{tabular}{|c|c|c|c|c|}
\hline $\begin{array}{l}\text { Categoria } \\
\text { ocupacional. }\end{array}$ & \multicolumn{2}{|c|}{ En $E^{\circ}$ de julio/70 } & \multicolumn{2}{|c|}{$\begin{array}{l}\text { Indice julio/ } 71=100 \\
1971\end{array}$} \\
\hline Obreros & 988.3 & $1,096.2$ & 100.0 & 110.9 \\
\hline Enpleados & $2,892.3$ & $2,727.6$ & 100.0 & 94.3 \\
\hline Trabajadores por cuenta propia & 1.664 .7 & $1,857.0$ & 100.0 & 111.6 \\
\hline Emp loa dores & $6,517.0$ & $5,852.0$ & 100.0 & 89.8 \\
\hline FrA & $2,541.2$ & $2,979.4$ & 100.0 & 117.2 \\
\hline Empleados domésticos & 778.7 & 857.7 & 100.0 & 110.2 \\
\hline Total & $2,022.3$ & $2,055.4$ & 100.0 & 101.6 \\
\hline
\end{tabular}

En 1972, el ingreso real promedio de "empleados domésticos" se incrementó en un $10.2 \%$ respecto a 1971 . Nuevamente este grupo contribuye a la equiparación debido a una mejora en su posición relativa, revirtiendo de este modo la tendencia del período anterior. La equiparación interna es contrarrestada por la tendencia a la concentración del ingreso dentro del grupo, que afecta a casi todos los tramos, siendo lo más significativo el alejamiento del tramo superior respecto a la media del grupo.

En 1972, la categoría "trabajadores por cuenta propia" sugiere un aumento del ingreso real promedio del orden de $11.6 \%$ respecto a 1971 . El aporte de la categoría a la equiparación general es prácticamente nulo. Es el resultado de dos movimientos contrapuestos: $a)$ una clara tendencia a la concentración interna del ingreso $\mathrm{y}, b$ ) una mejora de su posición relativa. La concentración es el resultado de la polarización interna que sugiere la mejora de la posición de los tramos de ingreso de más de $5 \mathrm{E}^{\circ}$ vitales y el deterioro de todos los tramos inferiores (excepto el más bajo).

Las tendencias generales que surgen del análisis son las siguientes: 
1. Con excepción de "empleados" y "empleadores", todas las categorias denotan un aumento del ingreso real promedio.

2. Continúa el movimiento general hacia una distribución más equitativa del ingreso observado en el período anterior.

3. Los cambios en las posiciones relativas de las categorías ocupacionales (intervarianzas) se pueden observar en la siguiente tabla:

Tabla 2

CAMBio de las posiciones relativas de las categorfas OCUPACIONALES (1971-1972)

\begin{tabular}{|c|c|c|c|c|}
\hline & \multicolumn{2}{|l|}{ Mejoran } & \multicolumn{2}{|c|}{ Empeoran } \\
\hline $\begin{array}{l}\text { Originalmente por debajo de la media } \\
\text { general }\end{array}$ & $\begin{array}{l}\text { Obreros } \\
\text { Trab. × CP } \\
\text { Empl. Domést. }\end{array}$ & $\begin{array}{l}(+) \\
(t) \\
(t)\end{array}$ & & \\
\hline $\begin{array}{l}\text { Originalmente por encima de la media } \\
\text { general }\end{array}$ & FFAA & $(-)$ & $\begin{array}{l}\text { Empleados } \\
\text { Empleadores }\end{array}$ & $(+)$ \\
\hline
\end{tabular}

Al comparar las tablas 1 y' 2 surge con nitidez que los cambios de posición relativa se producen en las categorías "trabajadores por cuenta propia" y "empleados domésticos", que pasan a compartir una situación similar a la de "obreros"; por otra parte, "empleados" pasa de una situación equivalente a la de "fuerzas armadas" a una similar a la de "empleadores".

4. Del mismo modo que en el periodo 70-71, la tendencia a una distribución más democrática del ingreso se debe en gran parte $(72.5 \%)$ al proceso de homogeneización interna del ingreso de las ocupaciones.

5. La tendencia general señalada en el punto anterior, es el resultado de movimientos internos de las categorías ocupacionales, y revisten una complejidad mucho mayor que la observada durante el período anterior.* Sin embargo, la mayor parte del movimiento reflejado por las intravarianzas, está determinado por la tendencia a la equiparación interna de "empleados" y "empleadores", que afecta a casi todos los tramos de sueldo vital de éstas, en coherencia con lo observado durante el período anterior.

Las categorías "obreros", "trabajadores por cuenta propia" y "empleados domésticos", denotan un leve proceso de concentración interna de su ingreso. Los tramos de sueldo vital medio e inferior sufren un retroceso de su posición relativa dentro de cada categoría, en tanto que los tramos superiores mejoran. Una excepción de esta tendencia: el tramo de sueldo más bajo en las tres categorías se aproxima levemente a la media. Para nuestro análisis, si bien respecto al período 1970-71 no se observan

* Ver Apéndice No 2. 
diferencias apreciables, en términos cuantitativos desde una perspectiva política la importancia es manifiesta.

El proceso de homogeneización interna que experimenta "fuerzas armadas" indica que se revierte la tendencia del período $1970-71$ por un lado, y se diferencia del que afectó a "empleados" y "empleadores" en 1971-72, pues en la distribución interna del ingreso de los militares, los tramos bajos de sueldo vital se aproximaron al promedio y el más alto se alejó. Es decir, la mayor homogeneidad total surge de un proceso equidistributivo que coexiste con un proceso concentrador más débil.

Las tendencias que surgen del análisis del período 1971-72 son de 2 tipos: a) las que reflejan una continuación de los procesos observados en el período 1970-71 y, b) los cambios y diferencias que requieren ser explicados.

Durante el segundo semestre de 1972 se produjo una revisión de la política económica del gobierno de la Unidad Popular, que implicó el cambio de las personas encargadas de su diseño y aplicación, así como la participación de los partidos que conformaban la coalición de gobierno. La discusión respecto de si estos cambios implicaron una política económica diferente o eran sólo reajustes en el modelo aplicado hasta entonces, no nos concierne, puesto que están fuera del período de relevamiento de la información utilizada (encuestas 1971-72). Las discrepancias observadas entre los dos períodos se explicarían entonces por diferencias en las condiciones de aplicación de la política económica.

Las condiciones imperantes en 1972 se pueden sintetizar en lo siguiente: i) una economía plenamente reactivada, en los límites cada vez más estrechos impuestos por la capacidad productiva y la capacidad de importar alimentos e insumos, así como por un alto nivel de ocupación de la fuerza de trabajo.

ii) Importante mejoramiento de los trabajadores durante 1971 en su participación en el ingreso total y diseño de una política económica para 1972 que tiende a mantener y mejorar esa nueva posición ganada por los mismos.

iii) El capital monopolista y sus aliados, internos y externos, desatan una fuerte ofensiva para resolver a su favor la lucha que se plantea en todos los terrenos, principalmente en el plano político. En el campo económico buscan bloquear el avance en las transformaciones básicas e invertir a su favor la distribución del ingreso total.*

Las precondiciones que permitían cierto éxito en la aplicación del modelo de reactivación económica en 1971 (capacidad instalada ociosa, alta tasa de desocupación y un volumen adecuado de divisas) en 1972 se habían prácticamente agotado. El cambio del nivel y composición de la demanda esperados con la redistribución del ingreso, se ven limitados con

* La Economia Chilena en 1972. Instituto de Economía y Planificación, Universidad de Chile, p. 204. 
la desaparición de las precondiciones. Una vez utilizada la capacidad ociosa, la demanda adicional producida por el aumento de los ingresos de los sectores populares puede traducirse en una mayor oferta, cuando se generan nuevas inversiones productivas en aquellas líneas de productos demandados.

Como ha sido señalado, el ingreso de los empleadores en 1971 muestra que la masa de ganancia no se incrementó hasta el nivel requerido para compensar la caída de la ganancia por unidad de producto; esto se refleja en la caída de su ingreso real promedio. Ante el deterioro de la tasa y de la masa de ganancia - y en las condiciones de la lucha política en Chile- difícilmente podía esperarse un aumento de la inversión privada productiva.*

Examinaremos a continuación, las medidas de política económica que afectaron a las categorías "empleados" y "empleadores", dado que la mayor parte de la variación en la distribución del ingreso durante el período 1971-72 se explica por el comportamiento de las mismas.

El aumento del ingreso real (ver cuadro núm. 9) comenzó a ser absorbido parcialmente por cambios en el nivel de precios: en el primer semestre de 1972, éste sufrió un alza que llegó al $27.7 \%$. La falta de inversiones y el alza general del ingreso real promedio, así como su distribución dieron lugar a la aceleración del proceso inflacionario. El Instituto de Economía y Planificación de la Universidad de Chile, dice al respecto:

Por la escasez relativa de los productos en el mercado normal y por los aumentos descontrolados de los precios en el mercado "negro", parte de los mayores ingresos monetarios de los trabajadores son esterilizados. Además hay otro efecto, las alzas de precios en el mercado normal autorizadas por el aumento en los costos de producción (alzas de las remuneraciones, precios más elevados de los insumos). .**

La aceleración del proceso inflacionario es uno de los elementos que arroja luz sobre las alteraciones de tendencia que sufre la distribución del ingreso en 1972 respecto a la de 1971; los otros elementos deben buscarse en la "ley de reajuste".

La "ley de reajuste de sueldos y salarios" (ley núm. 17654) contiene entre otras, las siguientes disposiciones: i) reajuste general de sueldos y salarios de acuerdo con el porcentaje de incremento del índice de precios al consumidor de enero a diciembre de 1971 (que fue del $22.1 \%$ ); $i$ ) elevación del salario mínimo para todos los obreros que percibían 30.00 escudos diarios ( $900.00 \mathrm{E}^{\circ}$ mensuales) que significó un alza del $50 \%$ respecto a 1971; iii) se estableció un sueldo mínimo de $1100 \mathrm{E}^{\circ}$ mensuales para todos los empleados, incluidos los recién incorporados al mercado

* Véase por ejemplo Instituto de Economía y Planificación: Op. cit., p. 385.

** Instituto de Economía y Planificación, Universidad de Chile: La Economía Chilena en 1972, p. 206. 
de trabajo. Con el objeto de favorecer la situación de los trabajadores del sector público se tomaron las siguientes medidas: mejoras especiales en las remuneraciones de los trabajadores de los servicios más postergados; incremento adicional del $10 \%$ sobre los sueldos ya reajustados de los trabajadores que percibieran una remuneración inferior a tres sueldos vitales; se fijó la asignación por colación en $\mathrm{E}^{\circ} \mathbf{1 0 . 0 0}$ por día de trabajo y se congelaron las que excedían ese monto; se concedió un aumento especial a los médicos y los profesores.*

La caída del ingreso real promedio de los empleados se debe a la diferencia entre el nivel de reajuste de los sueldos $(22.1 \%$ a partir de enero) y el alza de los precios $(27.7 \%$ de enero a junio de 1972). Ha sido demostrado que la contribución a la equidad en la distribución del ingreso que realiza la categoría "empleados" se debe a su homogeneización interna. Esto puede explicarse con las disposiciones de la ley de reajuste que otorgaron: mejoras especiales para los trabajadores con sueldos reajustados pero por debajo de los tres vitales; fijación del sueldo mínimo en $1100.00 \mathrm{E}^{\circ}$ para los empleados, y concesión de un aumento especial a médicos, funcionarios y profesores. El deterioro relativo de los tramos superiores de sueldo vital es el resultado de combinar el efecto del reajuste y de la inflación por un lado y de la elevación de los tramos de sueldo inferiores por el otro.

Los elementos que esclarecen la situación de los empleadores son los siguientes: por un lado, la política de fijación de precios y por el otro, los aumentos de salario y de precio de los insumos (acaecidos en un contexto de tensión social creciente).

En el caso que nos interesa, esto se hizo evidente en la conducta iniciada por los centros monopólicos ya en septiembre de 1970 y profundizada sistemáticamente a lo largo de todo el período. A la vez que subordinaban cualquier iniciativa económica a la necesidad de recuperar su preeminencia política, interrumpieron el funcionamiento normal del ciclo de producción y trataron de transformar todos sus activos en recursos liquidos. El segundo aspecto era simultáneamente una forma de poner la mayor cantidad posible de sus recursos al margen de una eventual expropiación y de crear problemas económicos al gobierno. Todo esto se manifestaba de diferentes maneras: detención de los programas de inversión para ampliar o mantener el aparato productivo; obstáculos al aumento del nivel de actividad, en cuanto significara nuevas contrataciones de personal o utilización adicional de capital; reducción crítica de los inventarios de materias primas, especialmente importadas; utilización de moneda en forma ilegal; fuga de divisas al exterior, utilización especulativa del capital líquido; estímulo a los aumentos exagerados de salarios para quebrar la política de contención de precios.**

* Instituto de Economía y Planificación. Universidad de Chile. Op. cit., pp. 250-251.

* Alberto Martínez: Op. cit., p. 50. 
Esta combinación de factores esclarece la caída del ingreso real promedio denotado por "empleadores" durante 1972 respecto de 1971 . El aporte de ésta a la equiparación de la distribución del ingreso se explicaba por movimientos de la inter y de la intravarianza de magnitudes similares. La posición relativa de esta categoría ocupacional dentro del conjunto es resultado del movimiento anteriormente descrito, así como de la decisión de los grupos de subordinar sus decisiones económicas a sus intereses políticos. Su homogeneización interna es producto del deterioro relativo sufrido por los tramos superiores de sueldo vital, hecho que surge como indicador de la eficacia de las medidas de política económica aplicadas a las grandes empresas.

La organización sindical de una mayor cantidad de trabajadores aseguró el cumplimiento de las leyes de reajuste; este hecho, sumado a la decisión de algunos empresarios de promover alzas de salario superiores a los niveles fijados por la ley, lleva a incrementar la proporción de ingresos que perciben los obreros y, en consecuencia a disminuir los tramos superiores de sueldo vital de los empleadores. Esta situación articulada con un control de precios más efectivo, dará como resultado la caída de los empleadores económicamente más poderosos.

La ley de reajuste permite comprender además, el alza del salario real de los obreros. La vigencia de disposiciones especiales que asignó un reajuste superior al $22.1 \%$ (por ejemplo, incremento del $50 \%$ del salario mínimo), permitió que los obreros pudiesen absorber el alza del $27.7 \%$ en los precios.

El cambio más importante de la distribución del ingreso de los obreros se manifiesta en la mejora de su posición relativa, producto del alza de nivel de los tramos superiores de sueldo vital. Esto explica igualmente la leve tendencia a la concentración del ingreso dentro de este grupo. El tamaño de las empresas en el caso analizado, reviste una importancia fundamental: tanto en las empresas privadas como en las estratégicas incorporadas al área de propiedad social es posible ejercer mayores presiones para obtener mejoras salariales. Podemos suponer que en ambos sectores se ubican los obreros de ingresos más altos debido al carácter más moderno de estas industrias.

Las fuerzas armadas continúan mostrando la misma tendencia a mejorar su posición relativa que durante el período anterior. La ley especial de reajuste para las fuerzas armadas y carabineros tiene que haber garantizado alzas en los sueldos, superiores a la tasa de inflación del primer semestre de 1972. Esto explica la mejora salarial del grupo cuando ya se ubicaba por encima del promedio general. La tendencia a la igualación del ingreso dentro de las fuerzas armadas se debe a una mejora relativa de aquellos tramos donde se ubican los oficiales de grados intermedios y menores.

El salario real promedio de los empleados domésticos se eleva durante el período considerado. Esto obedece a varios factores: mayor control del 
cumplimiento de las leyes que regulaban el trabajo doméstico (salarios, seguro social), un mercado de trabajo en expansión que abría alternativas laborales a los trabajadores domésticos y, un contexto de movilización general donde también ellos eran objeto de la estrategia encaminada a no dejar disponible ningún ámbito susceptible de ser influenciado políticamente.

Los trabajadores por cuenta propia son un grupo heterogéneo. Los cambios que se producen en su interior son erráticos y producto de varias fuentes. Sin embargo, es posible hacer algunas afirmaciones de carácter general. En primer lugar, considerado como categoría ocupacional, el alza del ingreso real que afecta a la mayoría de sus tramos de sueldo vital se traduce en una mejora de su posición relativa. Pero lo más importante fue el deterioro que sufrieron los dos tramos superiores (más de $10 \mathrm{E}^{\circ}$ vitales) donde probablemente se ubican los profesionales liberales, quienes vieron reducido su mercado de trabajo como consecuencia de la ampliación de los servicios sociales, tarea prioritaria que asumió el gobierno.

Hasta aquí se ha analizado la información para los períodos 1970-1971 y 1971-1972. En la próxima sección, y a modo de conclusión, se examinarán los cambios de la distribución del ingreso para el período en su conjunto, es decir, 1970-1972. El análisis se llevará a cabo explicitando las tendencias contradictorias y aquellas que se reforzaron de un período a otro.

3. A modo de conclusión: las tendencias generales mostradas por la distribución del ingreso entre 1970-1972

La información que servirá para fundamentar nuestras aseveraciones se encuentra én el apéndice núm. 3. En esta sección se explicitará la situación general de las categorías ocupacionales en 1972 comparándola con la de 1970. Pero a diferencia de las secciones anteriores, seguiremos estrictamente el orden impuesto por los datos. Se vinculará el análisis al contexto político donde tenían lugar los fenómenos examinados.

Consideramos imprescindible hacer un análisis político para entender los hechos ocurridos entre 1972 y 1973; sin embargo, el alcance de este estudio es de carácter eminentemente económico. Por lo tanto, reconocemos que la información utilizada disminuyó su significación al estar distorsionada por factores no mensurados (existencia y alcance del mercado negro, por ej.) que fueron la expresión de la determinación de los fenómenos económicos por los políticos, en esta coyuntura.

En el período que va de junio de 1970 a junio de 1972, el ingreso real promedio general sufrió un alza del $20.5 \%$. En ese periodo, el gobierno de la Unidad Popular sólo expidió dos leyes de reajuste de sueldos y salarios (además de las leyes especiales para las fuerzas armadas y carabineros). Todas las ocupaciones incrementaron su poder adquisitivo, excepto los empleadores, que sufrieron una pérdida de $33.7 \%$ en relación 
a 1970. Las fuerzas armadas tuvieron el alza más importante de ingreso real promedio, que alcanzó casi un $55 \%$; en el 2 \% lugar se ubicaron los cbreros que incrementaron en un $35 \%$ sus ingresos, luego los empleados domésticos con cerca de un $23 \%$, los trabajadores por cuenta propia, un $20.8 \%$, y finalmente los empleados, un $14.5 \%$.

Durante este período, más de la mitad de la tendencia general hacia la distribución más equitativa del ingreso es resultado de la caída constante de la posición denotada por "empleadores" combinada con un proceso sistemático de igualación interna de su distribución de ingresos. Si bien ya ha sido mencionada la política económica que subyace a estos fenómenos, la explicación sería incompleta si no se incorporaran al análisis los actores sociales que hasta aquí aparecen como categorías ocupacionales sujetas a una política de gobierno.

Hemos visto reflejarse hasta este punto, el enfrentamiento, en el terreno económico, entre el gobierno de la Unidad Popular y los sectores que tradicionalmente detentaron el poder en Chile hasta 1970. Este proceso era parte de la política de acumulación de poder del gobierno, con la perspectiva de transición hacia el socialismo, que se planteaba como objetivo el debilitamiento de la clase antagónica. En este marco se ubican, tanto la política económica descrita anteriormente, como los fenómenos observados en la distribución del ingreso. Pero, a partir de octubre de 1972, el enfrentamiento entre el gobierno y la clase dominante rebasó definitivamente el ámbito económico; por lo tanto, para comprender el desarrollo del proceso social, es restringida la utilidad del enfoque económico.

Por otra parte, la búsqueda de ampliación de la base social de apoyo por parte del gobierno también se refleja en los cambios que se han observado en la distribución del ingreso entre 1971 y 1972.

Los obreros constituían el eje de la coalición de partidos que apoyaba al gobierno: eran el centro de una propuesta de alianza de clases que permitiría simultáneamente ampliar la base de apoyo de la UP y aislar a la clase dominante. Este papel político que jugaban los obreros, aunado con los objetivos de justicia social expresados en el programa del gobierno, permiten comprender las medidas de política económica que ubicaron en una mejor posición relativa al grupo, con un mínimo de igualación interna en 1971 y con una concentración del ingreso mayor en 1972 que en 1971.

La explicación de las diferencias observadas entre 1971 y 1972 se debe buscar no sólo en el análisis económico, sino también en los cambios impuestos por la dinámica del conflicto político. Los límites de la reactivación económica en términos de inversión, se debieron a una decisión política que instrumentaron los empresarios al no responder a los estímulos de la demanda efectiva. El modelo de reactivación económica del gobierno suponía un tipo de racionalidad en los inversionistas que los conduciría a buscar la recuperación de los niveles de ganancia a través de un au- 
mento de la producción que compensara la pérdida del nivel de ganancia por unidad.

La eventualidad de una reacción política que buscara entorpecer la recuperación económica suspendiendo las inversiones estaba prevista, ya que se conocía y se hacía uso de instrumentos legales que permitían la requisición e intervención de industrias que no satisficieran la demanda de bienes de necesidad generalizada.

El problema se trasladó desde otro ámbito, puesto que las decisiones fueron, en esta situación, objeto de controversia política.

En las palabras del ministro de Economía, encargado de la aplicación de este programa:

Sin desconocer que hay, desde este ángulo dos momentos distintos dentro del período del Gobierno Popular, marcados por los índices que van, el primero, desde noviembre de 1970 hasta mediados de 1972, y el segundo desde entonces hasta la fecha del golpe militar. Momentos respecto de los cuales se ha sugerido frecuente y erróneamente, que se diferencian en tanto en el segundo habían aflorado los efectos desatados por la política de reactivación desarrollada en la primera etapa. La realidad es otra: la diferenciación estriba más bien en que en el segundo momento ya no pudimos desarrollar nuestra política."

Coincidimos con esta periodización propuesta por Pedro Vuskovic; sin embargo, es de notar que el cambio cualitativo ocurrido en octubre de 1972 es el resultado de un proceso en el que se diferencian claramente dos momentos, y donde se aplica una política económica unitaria. Se destacan ciertos cambios en las condiciones que enmarcan el proceso y que determinan algunas de las diferencias observadas.

El doble movimiento de la distribución del ingreso dentro del grupo de los obreros obedece a modificaciones de las condiciones generales, que determinan diferentes niveles y características de la movilización obrera. En 1971, el cambio que experimenta el poder adquisitivo de los obreros obedece básicamente al diseño de la política económica. En 1972, los obreros se movilizan en defensa de sus salarios reales amenazados por la aceleración del proceso inflacionario en condiciones muy favorables: 1) agudización del conflicto político, mediante el cual el gobierno busca el apoyo obrero; $\mathrm{y}, 2$ ) avance y consolidación del cambio de la forma de propiedad expresada en la creación del área de propiedad social y mixta de la economía.

Sin embargo, en el transcurso de este mismo proceso, estas transformaciones no afectan de manera uniforme al conjunto de la clase obrera; esto se traduce en diferencias en el poder de negociación, en la concentración del ingreso dentro del grupo obrero y en su diferenciación interna.

* Pedro Vuskovic: Una sola lucha, p. 85 (subrayado del autor). 
Una de las causas de la polarización de la distribución del ingreso dentro del grupo de los obreros es señalada por Alberto Martínez:

Los antecedentes anteriores confirman el elevado grado de concentración de la propiedad de los recursos fundamentales. En estas circunstancias, la formación del APSM afectaba a un grupo particularmente reducido de empresas y personas. Por otra parte, el hecho de que allí se encontraran las actividades de mayor desarrollo técnico relativo y de productividad más elevada, implicaba que sólo una parte reducida de los trabajadores se beneficiaría directamente por la modificación en las relaciones de producción interna de las empresas. No más del $20 \%$ de los obreros y empleados no agrícolas, y alrededor del $30 \%$ de los obreros y empleados industriales. Su complemento era una cantidad excepcionalmente elevada de unidades $\mathrm{y}$ de trabajadores, sobre todo industriales $\mathbf{y}$ comenciales, que permanecerían en el sector privado.*

En el período 1970-1972, el grupo de los empleados contribuyen a una distribución más equitativa del ingreso. Sin embargo, hay que destacar que resulta casi en su totalidad de un proceso de equidistribución interna. Es una tendencia que se mantiene y se refuerza en los dos períodos considerados. No ocurre lo mismo con su posición relativa, que mejora en 1971 con respecto a 1970 y empeora en 1972 respecto de 1971, en ambos casos levemente. Esto se refleja a su vez en todos los tramos de ingreso, como se observa en el cuadro siguiente:

Cuadro 10

INGRESO PROMEDIO DE LOS EMPLEADOS POR TRAMOS DE SUELDO VITAL EN $E^{\circ}$ DE JUNIO DE 1970

\begin{tabular}{|c|c|c|c|c|c|c|c|c|c|}
\hline \multicolumn{4}{|c|}{$\begin{array}{c}\text { Tramos } \\
(\text { fan: } j)\end{array}$} & \multirow{2}{*}{\multicolumn{2}{|c|}{$\frac{1970}{105.8}$}} & \multirow{2}{*}{\multicolumn{2}{|c|}{$\frac{1971}{119.1}$}} & \multirow{2}{*}{\multicolumn{2}{|c|}{$\frac{1972}{189.4}$}} \\
\hline 0 & a & 0.5 & & & & & & & \\
\hline 0.5 & $\mathrm{a}$ & 1.0 & & & 527.9 & & 585.9 & & 519.9 \\
\hline 1.0 & $\mathbf{a}$ & 1.5 & . & & 779.6 & & 847.5 & & 771.8 \\
\hline 1.5 & $a$ & 2.5 & & 1 & 226.3 & 1 & 390.2 & 1 & 231.6 \\
\hline 2.5 & $-a$ & 5.0 & & 2 & 274.9 & 2 & 526.2 & 2 & 204.5 \\
\hline 5.0 & $\mathrm{a}$ & 10.0 & & 4 & 397.8 & 4 & 757.6 & $4^{\circ}$ & 236.8 \\
\hline 10.0 & $\mathrm{a}$ & 20.0 & & 8 & 372.5 & 9 & 230.3 & 7 & 904.2 \\
\hline mas de & & 20 & & 18 & 231.6 & 16 & 793.1 & 13 & 983.4 \\
\hline Ingres & me & 0 total & & 2 & 381.3 & 2 & $892: 3$ & 2 & 727.6 \\
\hline
\end{tabular}

* Alberto Martínez: Op. cit., pp. 47-48. 
La política económica de la UP, que buscaba un cambio en el nivel y composición de la demanda en favor de los productos de consumo popular, puede dar un marco para la comprensión del fenómeno expuesto.

La variación de la posición relativa, una mejora en 1971 y posterior caída en 1972, tornan inadecuada la explicación en términos estrictamente económicos. Parecería haber una decisión política detrás de estos movimientos, que estaría expresando actitudes dispares respecto a la necesidad que tenía el gobierno de recibir apoyo de las clases medias. Aparentemente, la firmeza con la que el gobierno reduce en 1972 las ventajas relativas que habían logrado los empleados en 1971, que reflejaban una cierta complacencia con miras a evitar conflictos y promover una alianza de clases amplia, obedecía a la idea de que en una situación de conflicto agudo y de restricción económica, era primordial asegurar el apoyo abuso (redistribución a su favor); el apoyo del sector representado por los empleados surgiría como consecuencia de la evolución de la correlación de fuerzas políticas y no del otorgamiento de ventajas económicas.

En el período 1970-1972, los trabajadores por cuenta propia experimentaron un proceso de igualación en la distribución interna del ingreso. $\mathrm{Su}$ posición relativa permaneció estable, aun cuando oculta un deterioro en 1971 respecto a 1970 y una mejora en 1972 respecto a 1971. También la homogeneización interna resulta de movimientos contrarios, uno más fuerte, de igualación, en el primer período, contrarrestado por una leve tendencia a la concentración en el segundo.

Los movimientos erráticos de la totalidad del período son el resultado de movimientos aún más erráticos de los tramos de sueldo vital de los dos subperiodos, consecuencia de haber sido definida la categoría "trabajadores por cuenta propia", con criterios meramente estadísticos. Al no representar a ningún grupo social específico, la política económica no pudo responder a sus intereses concretos. La información tabulada según los tramos de sueldo vital contiene ocupaciones tan diversas que resulta imposible vincularlas a las clases sociales.

La heterogeneidad ocupacional de los trabajadores por cuenta propia incluye a trabajadores dedicados a la producción y comercialización de servicios menores (plomeros, aseadores, etc.), a comerciantes ambulantes, pequeños comerciantes, artesanos, pequeños empresarios (con dos trabajadores o menos bajo su control) y a profesionales liberales.

De lo anterior se desprende que los individuos que conforman la ca. tegoría "trabajadores por cuenta propia" se vinculan con mercados di. versos (donde se ofertan bienes y servicios) que no muestran tendencias similares. Las políticas económicas que se diseñaron con el fin de satisfacer intereses de grupos sociales específicos, tuvieron efecto residual sobre esta categoría ocupacional. Por ejemplo, es sabido que en su interior se encuentra una masa flotante de trabajadores que buscan concretar al. ternativas laborales diferentes en la medida en que se amplían las oportunidades de trabajo; ésta fue la situación que se presentó al concretarse 
la política de absorción del desempleo de la Unidad Popular. 1971, año exitoso para la política de reactivación económica: las actividades comerciales se expandieron y la parte del ingreso correspondiente al comercio, en particular, el vinculado por los artesanos y pequeños productores, debería haber sido favorecida; los precios del mercado estaban dados y conservar la masa de ganancia sólo requería aumentar la producción. Sin embargo, la demanda expandida requería un aumento de producción, que no pudo realizarse debido, posiblemente, a dificultades financieras propias del sector, ajenas a decisiones políticas.

Los datos utilizados no permiten profundizar el análisis de esta categoría, ya que engloba a varios grupos sociales que al tener intereses divergentes reaccionan de modo diferencial ante las medidas de política económica globales.

La mejora relativa de la posición de las fuerzas armadas dentro de la distribución del ingreso entre 1970 y 1972, es el resultado de un movimiento sistemático y en el mismo sentido ocurrido en 1971 comparado con el de 1970, y de 1972 comparado con el de 1971. Se agrega a este movimiento, un proceso de concentración interna del ingreso en los niveles superiores de la oficialidad. Estas dos características centrales de la evolución de la distribución del ingreso de las fuerzas armadas, reflejan con nitidez, las políticas del gobierno de la Unidad Popular para las FFAA: beneficio económico del conjunto y en particular de la oficialidad, a fin de lograr un cierto grado de cooptación que no interfiriera en las estructuras jerárquicas internas.

La categoría "empleados domésticos" indica que es la que contribuye más débilmente al proceso de igualación de la distribución del ingreso entre 1970 y 1972. Esta contribución puede percibirse como integrada por una mejora de su posición relativa y una tendencia a la equidistribución interna. Este aporte a la igualación resulta de la tendencia sostenida a lo largo de los dos subperíodos analizados (1970-1971 y 1971-1972); sin embargo, en el primero, "empleados domésticos" señala una caída de la posición relativa y en el segundo, un alza. Internamente, en 1970-1971, denota una tendencia a la equidistribución y en 1971-1972 una tendençia a la concentración. Es decir, entre los dos subperíodos los cambios fueron inversos.

Las dificultades para interpretar los movimientos de la categoría "trabajadores por cuenta propia" se repiten en el caso "empleados domésticos", pero su origen es distinto. En efecto, en el primer grupo tenían su origen en la forma de elaborar la información, mientras que para "empleados domésticos" surgen por limitaciones de la técnica utilizada. Es conocida la sensibilidad del promedio respecto de los valores extremos y sus consecuencias sobre las funciones, como es el caso de la varianza.

$\mathrm{Al}$ observar los datos originales, se desprende que la variación de la distribución interna del ingreso para 1970-1971 se debe casi en su totalidad, a la desaparición de dos observaciones (una en el tramo de 5 a 
$20 \mathrm{E}^{\circ}$ de salario vital y otra en el de 10 a 20 ), sobre un total de 502 casos. Algo similar acontece entre 1971 y 1972, donde la tendencia a la concentración interna, ya señalada, se explica en gran parte por la aparición de tres observaciones en la categoría más alta (de 5 a $10 \mathrm{E}^{\circ}$ de salario vital), de un total de 419 observaciones. Los leves cambios observados en "empleados domésticos" pueden ser, entonces, consecuencia de fluctuaciones muestrales, que no pueden ser explicadas por la política económica aplicada.

La imposibilidad de hacer un análisis sustantivo de "empleados domésticos", que deriva de la escasez de información respecto de algunos tramos, no es válida en el caso de "fuerzas armadas" donde la escala de ingresos está en correspondencia con la escala jerárquica institucional; por otra parte, los datos no presentan las irregularidades que se observan en "empleados domésticos".

Como conclusión de este trabajo se destacarán las tendencias más importantes del análisis global:

i) durante el período en que gobernó la Unidad Popular hubo una persistente tendencia a la igualación de la distribución del ingreso.

ii) en la tabla número 3 , se exponen las categorías ocupacionales que sufrieron mejoras o deterioros de la posición relativa en 1972 respecto de 1970.

Tabla 3

Cambio de la posición relativa de las categorías OCUPACIONALES (1970-1972)

\begin{tabular}{llll}
\hline & & Mejoran & Empeoran \\
\hline $\begin{array}{l}\text { Originalmente por debajo de la media } \\
\text { general }\end{array}$ & $\begin{array}{l}\text { Obreros } \\
\text { Trab. } \times \text { CP } \\
\text { Empl. Domést. }(+)\end{array}$ & \\
$\begin{array}{l}\text { Originalmente por encima de la media } \\
\text { general }\end{array}$ & FFAA & $(-)$ & Empleados \\
\hline
\end{tabular}

iii) el proceso general de equidistribución observado se debe, en gran parte, a una marcada tendencia a la equidistribución interna del in. greso de todas las categorías ocupacionales, con excepción de "fuerzas armadas".

iv) aun cuando todas las ocupaciones sufrieran alteraciones en sus posiciones relativas y en la distribución interna del ingreso, los cambios expresados por las varianzas totales prácticamente corresponden a las categorías "empleadores" y "empleados". Las demás ocupaciones sufren 
alteraciones menores que no ameritan análisis detallados, a excepción de "obreros", dada su relevancia política.

v) los cambios globales descritos para el periodo 1970-1972 consisten en movimientos diferenciales entre las categorías ocupacionales así como intra-categorías en cada subperíodo.

El subperíodo 1970-1971 representa la más plena y exitosa aplicación del modelo de reactivación económica y de la contención del conflicto social dentro de los marcos institucionales. Dentro de este marco explicativo se debe entender: 1) la mejora absoluta señalada por la categoría "empleados" y su caída en relación a las restantes ocupaciones; 2) el deterioro de "empleadores"; y, 3) la tendencia a la equiparación intraocupacional del ingreso. En el subperíodo 1971-1972, el modelo de reactivación económica alcanza sus límites políticos, dando lugar al inicio del conflicto socio-político abierto, que se ubica fuera del período analizado. "Empleadores" continúa denotando la tendencia al deterioro y "empleados" señala el debilitamiento de la posición que obedece, posiblemente, no tanto a una mera decisión de política económica, sino a la conducta probablo que el sector representado por ella iba a desarrollar en el conflicto que se iniciaba.

vi) la vinculación entre "política" y "política-económica", es coherente en el caso de los obreros, base fundamental de apoyo de la Unidad Popular. En consistencia con esto, mejoran su participación relativa en la distribución del ingreso y en el primer subperíodo exhiben también un proceso de equidistribución interna, que se revierte en 1971-1972, probablemente como consecuencia de enfrentar la agudización del conflicto social desde una posición de poder nunca antes alcanzada, pero que producía, al mismo tiempo, una diferenciación interna cuyo reflejo es la concentración interna del ingreso. Políticamente, esta última caracterización no produce una división de la clase que se considere fundamental para el proceso político que se desarrollaba.

\section{BIBLIOGRAFIA}

Programa de la Unidad Popular. Editorial PLA, Santiago, Chile, 1970.

La economía chilena en 1972. Instituto de Economía y Planificación, Universidad de Chile. Santiago, Chile, 1973.

La economia chilena en 1971. Instituto de Economía, Universidad de Chile. Santiago, Chile, 1972.

Alberto Martínez, El área de propiedad social y mixta (APSM) del sector industrial durante el gobierno de la UP; UNAM. México. Investigación Económica Nueva Época № 2. Abril-junio de 1977.

Arturo León, Antecedentes para el análisis de la distribución personal y familiar del ingreso. Chile, 1970-1973. Proelce, Santiago, Chile, 1976. 
Ackermann y Cortés, Concentración y democratización. Un alcance metodológico técnico sobre el estudio de la distribución.

Pedro Vuskovic, Una sola lucha. Editorial Nuestro Tiempo. México, 1978.

Pedro Vuskovic, Distribución del ingreso y opciones de desarrollo. Economía Politica de la Unidad Popular. Editorial Barcelona, 1975.

Stefan de Vylder, Allende's Chile: the political economy of the rise and fall of the Unidad Popular. Cambridge University Press, 1976. 
Apéndice 1

CONTRIBUCIÓN DE CADA TRAMO DE INGRESOS, EN SUELDO VITAL, A LA VARIACIÓN DE LAS INTRAVARIANZAS ENTRE 1970 Y 1971 SEGÚN LA CATEGORÍA OCUPACIONAL

\begin{tabular}{|c|c|c|c|c|c|c|c|c|}
\hline \multicolumn{3}{|c|}{$\begin{array}{l}\text { Tramos de ingreso } \\
\text { en } \\
\text { sue } 2 \text { dos vitales }\end{array}$} & \multirow{2}{*}{$\frac{\text { Obreros }}{0.0017}$} & \multirow{2}{*}{$\frac{\text { Empleados }}{0.0079}$} & \multirow{2}{*}{$\frac{\text { Trab. } x \text { C.P. }}{0.0059}$} & \multirow{2}{*}{$\frac{\text { Empleadores }}{-0.0015}$} & \multirow{2}{*}{ FFAA } & \multirow{2}{*}{$\frac{\begin{array}{l}\text { Emp leados } \\
\text { domesticos }\end{array}}{0.0006}$} \\
\hline 0. & a & 0.5 & & & & & & \\
\hline 0.5 & $\bar{a}$ & 1.0 & 0.0001 & 0.0278 & 0.0033 & 0.0080 & 0.0002 & 0.0000 \\
\hline 1.0 & a & 1.5 & -0.0017 & 0.0055 & -0.0024 & 0.0003 & 0.0003 & 0.0000 (k) \\
\hline 1.5 & a & 2.5 & $0.0031(*)$ & -0.0052 & -0.0030 & 0.0186 & -0.0002 & 0.0006 \\
\hline 2.5 & a & 5.0 & 0.0024 & -0.0091 & $0.0045(k)$ & 0.0382 & $-0.0008(x)$ & -0.0005 \\
\hline 5.0 & a & 10.0 & -0.0026 & $0.0198(*)$ & 0.0024 & 0.0273 & 0.0016 & 0.0001 \\
\hline 10.0 & a & 20.0 & 0.0038 & 0.0429 & 0.0265 & $-0.0098(*)$ & -0.0017 & 0.0053 \\
\hline Más de & & 20.0 & 0.0000 & 0.2683 & 0.0158 & 0.1464 & 0.0000 & 0.0000 \\
\hline Intrava & riar & & 0.0068 & 0.3569 & 0.0530 & 0.2270 & -0.0005 & 0.0051 \\
\hline
\end{tabular}

* Ubicación de la media 
Apéndice 2

CONTRIBUCIÓN DE CADA TRAMO DE INGRESO, EN SUELDO VITAL, A LA VARIACIÓN DE LAS INTRAVARIANZAS ENTRE 1971 Y 1972 SEGÚN LA CATEGORÍA OCUPACIONAL

\begin{tabular}{|c|c|c|c|c|c|c|c|c|}
\hline \multicolumn{3}{|c|}{$\begin{array}{l}\text { Tramos de ingreso } \\
\text { sueldon vitalmat }\end{array}$} & \multirow{2}{*}{$\frac{\text { Obrexos }}{0.0006}$} & \multirow{2}{*}{$\frac{\text { Empleados }}{0.0017}$} & \multirow{2}{*}{$\frac{\text { Trab. X C.P. }}{0.0024}$} & \multirow{2}{*}{$\frac{\text { Empleadores }}{0.0003}$} & \multirow{2}{*}{$\frac{\text { FFAA }}{0.0000}$} & \multirow{2}{*}{$\frac{\begin{array}{l}\text { Emp leados } \\
\text { domés ti cos }\end{array}}{0.0003}$} \\
\hline 0 & $a$ & 0.5 & & & & & & \\
\hline 0.5 & a. & 1.0 & -0.0004 & 0.0143 & -0.0011 & 0.0003 & 0.0000 & -0.0002 \\
\hline 1.0 & a & 1.5 & -0.0015 & 0.0088 & -0.0019 & 0.0075 & 0.0012 & $-0.0001(A)$ \\
\hline 1.5 & a & 2.5 & $0.0018(*)$ & 0.0057 & -0.0035 & 0.0031 & 0.0004 & 0.0006 \\
\hline 2.5 & a & 5.0 & 0.0015 & -0.0053 & $0.0055 *$ & 0.0034 & -0.0008 & -0.0007 \\
\hline 5.0 & a & 10.0 & -0.0043 & $0.0154(*)$ & 0.0053 & -0.0002 & 0.0030 & -0.0016 \\
\hline 10.0 & a & 20.0 & -0.0022 & 0.0285 & -0.0101 & $0.0038(*)$ & -0.0017 & 0.0000 \\
\hline Más de & 20.0 & & 0.0000 & 0.1332 & -0.0001 & 0.0217 & 0.0000 & 0.0000 \\
\hline Intra & arianza & & -0.0046 & 0.2024 & -0.0036 & 0.0399 & 0.0020 & -0.0017 \\
\hline
\end{tabular}

* Ubicación de la media. 


\section{Apéndice 3}

DESCOMPOSICIÓN DE LA VARIANZA DEL INGRESO ENTRE 1970 y 1972 CORREGIDO POR EFECTO ESCALA

\begin{tabular}{lccc}
\hline $\begin{array}{c}\text { Categorsa } \\
\text { Ocupacional }\end{array}$ & $\begin{array}{c}\text { Varianza } \\
\text { total }\end{array}$ & Intervarianza & Intravarianza \\
\hline Obreros & 0.0359 & 0.0290 & 0.0069 \\
Empleados & 0.3689 & 0.0119 & 0.3570 \\
Trabajadores por cuenta propia & 0.0531 & 0.0000 & 0.0531 \\
Empleadores & 0.5390 & 0.3120 & 0.2270 \\
FFAA & -0.0021 & -0.0015 & -0.0006 \\
Empleados domésticos & 0.0135 & 0.0074 & 0.0061 \\
\cline { 2 - 4 } & 1.0083 & 0.3588 & 0.6495 \\
\hline
\end{tabular}




\section{Apéndice 4}

CONTRIBUCIÓN DE CADA TRAMO DE INGRESO, EN SUELDOS VITALES, A LA VARIACIÓN DE LAS INTRAVARIANZAS ENTRE 1970 Y 1972 POR CATEGORÍAS OCUPACIONALES

\begin{tabular}{|c|c|c|c|c|c|c|c|c|}
\hline \multicolumn{3}{|c|}{$\begin{array}{l}\text { Tramos de ingreso } \\
\text { sueidon en }\end{array}$} & \multirow{2}{*}{ Obreros } & \multirow{2}{*}{$\frac{\text { Empleados }}{0.0062}$} & \multirow{2}{*}{$\frac{\text { Trab. X C.P. }}{0.0036}$} & \multirow{2}{*}{$\begin{array}{l}\text { Empleadores } \\
-0.0019\end{array}$} & \multirow{2}{*}{$\frac{\text { EFAA }}{0.0000}$} & \multirow{2}{*}{$\frac{\begin{array}{l}\text { Empleados } \\
\text { domésticos }\end{array}}{0.0002}$} \\
\hline 0 & $\mathbf{a}$ & 0.5 & & & & & & \\
\hline 3.5 & a & 1.0 & 0.0005 & 0.0134 & 0.0044 & 0.0076 & 0.0002 & 0.0002 \\
\hline 1.0 & a & 1.5 & -0.0003 & -0.0033 & -0.0004 & -0.0075 & -0.0008 & $0.0000 \quad(\%)$ \\
\hline 1.5. & a & 2.5 & $0.0014(*)$ & -0.0119 & 0.0005 & 0.0156 & -0.0005 & 0.0000 \\
\hline 2.5 & a & 5.0 & 0.0009 & -0.0038 & $0.0010(*)$ & 0.0347 & $0.0001(k)$ & 0.0003 \\
\hline 5.0 & a & 10.0 & 0.0018 & 0.0044 & -0.0028 & 0.0274 & -0.0014 & 0.0017 \\
\hline 10.0 & a & 20.0 & 0.0080 & 0.0144 & 0.0366 & -0.0135 & 0.0000 & 0.0053 \\
\hline Mâs da & & 20.0 & 0.0000 & 0.1352 & 0.0159 & 0.1247 & 0.0000 & 0.0000 \\
\hline \multicolumn{3}{|c|}{ Intravarianza } & 0.0068 & 0.3569 & 0.0530 & 0.2270 & -0.0006 & 0.0061 \\
\hline
\end{tabular}

* Ubicación de la media. 
Apéndice 5

INGRESO REAL PROMEDIO DE JUNIO DE CADA AÑo EXPRESADO EN E ${ }^{\circ}$ DE JULIO DE 1970

\begin{tabular}{lcccc}
\hline $\begin{array}{c}\text { Categoria } \\
\text { Ocupacional }\end{array}$ & $\begin{array}{c}\text { Promedio en EO de julio de } 1970 \\
1970\end{array}$ & $\begin{array}{c}\text { Indice julio de } 1970=100 \\
1970\end{array}$ \\
\hline Obreros & 809.3 & 1096.2 & 100.0 & 135.0 \\
Emp leados & 2381.3 & 2727.6 & 100.0 & 114.5 \\
Trabajadores por suenta propia & 1536.9 & 1857.0 & 100.0 & 120.8 \\
Emp leadores & 8822.5 & 5852.0 & 100.0 & 66.3 \\
FraA & 1923.4 & 2979.4 & 100.0 & 154.9 \\
Empl. domésticos & 698.6 & 857.7 & 100.0 & 122.8 \\
Promedio & 1705.1 & 2055.4 & 100.0 & 120.5
\end{tabular}

